\title{
NÚMERO EXTRAORDINARIO
}

EL EXILIO REPUBLICANO Y LOS CAMPOS DE CONCENTRACIÓN NAZIS

\author{
Marco Histórico y Teórico
}

\section{RESISTENCIA, DEPORTACIÓN Y POLÍTICAS DE LA MEMORIA. ESPAÑOLES EN FRANCIA 1940-1945}

\author{
Resistance, deportation and memory policies. Spanish in France \\ 1940-1945
}

\author{
Diego Gaspar Celaya \\ Universidad de Alcalá (UAH)
}

Recibido: 16-02-2018 - Aceptado: 14-II-2018

Cómo citar este artículo/Citation:

Diego GASPAR CELAYA, "Resistencia, deportación y políticas de memoria. Españoles en Francia 1940-1945”, Hispania Nova, $\mathrm{n}^{\circ} \mathrm{I}$ extraordinario (2019), págs. 66 a 99.

DOI: https://doi.org/10.20318/hn.2019.4721
Copyright: (c) HISPANIA NOVA es una revista debidamente registrada, con ISSN I I38-73I9 y Depósito Legal M 9472-1998. Los textos publicados en esta revista están -si no se indica lo contrario- bajo una licencia Reconocimiento-Sin obras derivadas 3.0 España de Creative Commons. Puede copiarlos, distribuirlos y comunicarlos públicamente siempre que cite su autor y la revista y la institución que los publica y no haga con ellos obras derivadas. La licencia completa se puede consultar en: http://creativecommons.org/licenses/by-nd/3.0/es/deed.es
Resumen: Entre 1940 y 1945, más de 9.000 españoles fueron deportados e internados en campos nazis. Durante décadas, la sociedad española fue deliberadamente privada de la suerte de sus compatriotas. Sin embargo, cuando a comienzos de los años noventa, la deportación española logró finalmente atraer la atención de profesionales y medios de comunicación, ello se tradujo en la identificación y estudio de los españoles deportados, de sus itinerarios vitales $y$ de sus experiencias de encierro. Este artículo pretende contribuir a ampliar nuestro conocimiento sobre la deportación española a través del análisis de los expedientes personales de españoles homologados como deportados internados resistentes (DIR) por las autoridades francesas. Una fuente, inédita hasta ahora en su estudio que, a su vez nos permitirá profundizar en la relación existente entre el internamiento de españoles en campos nazis y la participación de éstos en la Resistencia en Francia.

Palabras clave: resistencia, deportación, internamiento, refugiados españoles, CTE, exilio español, DIR.

\begin{abstract}
Between 1940 and 1945, more than 9,000 Spaniards were deported and interned in Nazi camps. For decades, Spanish society was deprived of the fate of its compatriots. However, when the Spanish deportation finally attracted the attention of professionals and the media, in the early 1990s, this resulted in the identification and study of the deported Spaniards, their life-itineraries and their experiences of internment. This article intends to contribute to expand our knowledge about Spanish deportation, through the analysis of the Spanish deported interned resisters (DIR) records conserved on French Defence archives, a novel source on Spanish deportation study that it will allow us to deepen on the relationship between the internment of Spaniards in Nazi camps and their participation in the Resistance in France.
\end{abstract}

Keywords: resistance, deportation, internment, Spanish refugees, CTE, Spanish exile, DIR.. 
Entre 1940 y 1945 más de 9.000 españoles fueron internados en campos nazis, en su mayoría en Mauthausen y sus anexos, pero también en Buchenwald, Sachsenhausen, Dachau o Neuengamme entre otros; no en vano, la mayor parte de los principales recintos del "universo concentracionario" nazi contaron en algún momento con presos españoles entre sus internos. ${ }^{1}$ El 5 de mayo de 1945 , al tiempo que tropas de la segunda división blindada que comandaba el general Leclerc, entre las que formaban cientos de soldados españoles, participaban en la toma del Nido del Águila de Hitler (Keh/steinhaus) en los Alpes bávaros; soldados norteamericanos alcanzaban el archipiélago Mauthausen. ${ }^{2}$ A su llegada al campo central -al día siguiente- "los españoles antifascistas" saludaron a las "tropas libertadoras". En cinco años, más de 4.800 habían asesinados en él y en sus anexos. ${ }^{3}$

Durante décadas, la sociedad española fue deliberadamente privada de la suerte de sus compatriotas internados en campos nazis a través de una doble censura franco-española de los recuerdos del conflicto mundial en posguerra. Sin embargo, cuando a comienzos de los años noventa del siglo XX, la deportación española logró finalmente atraer la atención de profesionales de la historia y medios de comunicación a ambos lados de los Pirineos, ello se tradujo en la progresiva y sistemática identificación de los deportados españoles y en el estudio de sus itinerarios vitales e internamiento.

\footnotetext{
${ }^{1}$ David ROUSSET, L'Univers concentrationnaire, 1946, París, Éditions de Minuit, 1965.

${ }^{2}$ Aleksandr Isaevich SOLZHENITSYN, Archipiélago Gulag : Ensayo de investigación literaria : 19181956, Barcelona, Tusquets, 2005; D. WINGEATE PIKE, Españoles en el holocausto. Vida y muerte de los republicanos en Mauthausen, Barcelona, Mondadori, 2003.

${ }^{3}$ Benito BERMEJO y Sandra CHECA, Libro memorial. Españoles deportados a los campos nazis (19401945), Madrid, Secretaría General Técnica. Subdirección General de Archivos Estatales, 2006; Carlos HERNÁNDEZ DE MIGUEL, Los últimos españoles de Mauthausen, Barcelona, Ediciones B, 2015.
} 
En los últimos años nuevas fuentes se han revelado especialmente interesantes a la hora de profundizar en esas historias de vida y encierro. De entre todas ellas, este artículo esta dedicado a analizar los expedientes personales de los españoles y españolas homologados como deportados internados resistentes (DIR) por las autoridades francesas en posguerra. Una fuente que, tal y como veremos a continuación, resulta de especial relevancia para ampliar nuestro conocimiento sobre la deportación española, aportando un nivel de detalle hasta ahora únicamente accesible a través del análisis y comparación de los testimonios de aquellos que sufrieron en primera persona el encierro en los campos nazis. Una fuente cuyo estudio me ha permitido profundizar tanto en la compleja relación que presenta la participación de españoles y españolas en la Resistencia en Francia y su deportación a campos nazis; como en la construcción en posguerra de una definición de restrictiva, masculina y militar de Resistencia sobre la que reposa la legislación francesa encargada de evaluar y reconocer los servicios prestados por un voluntario o voluntaria, nacional o extranjero, en la lucha contra el ocupante alemán y su socio radicado en Vichy.

\section{UNA DEFINICIÓN RESTRICTIVA}

Establecer una definición de la Resistencia en Francia ha sido, y continúa siendo, una tarea compleja y sensible dada la naturaleza, diversidad y heterogeneidad de formas, movimientos, organizaciones, compromisos y acciones en que se manifestó el fenómeno resistente. Entre los historiadores pioneros que aceptaron el reto de conceptualizarlo cabe destacar a Henri Michel, quien definió a la Resistencia como una doble lucha, de un lado la patriótica llevada a cabo "por la liberación del suelo nacional", y del otro la ideológica "por la dignidad del hombre". Tras ella llegó la propuesta del holandés Louis de Jong: "toda acción destinada a impedir la realización de los objetivos del ocupante", y/o las fórmulas de François Bédarida, Laurent Douzou o François Marcot entre otros. Sin embargo, entre todas, la que durante años ha gozado de una mayor aceptación entre la comunidad científica es la aportada por Bédarida en 1986: "una acción clandestina realizada en nombre de la libertad de la nación y de la dignidad de la persona humana por voluntarios que se organizaron para 
luchar contra la dominación (ocupación) de un régimen nazi, fascista o aliado". ${ }^{4}$ No obstante, gracias al notable avance que ha acusado la historiografía de la Resistencia en los últimos treinta años, nuevas investigaciones dedicadas a profundizar en su historia social han hecho posible profundizar en los aspectos socio-culturales del fenómeno y en sus protagonistas, poniendo a su vez de manifiesto el peso específico que toda una generación de historiadores franceses ha tenido, y tiene, en este proceso evolutivo. ${ }^{5}$ Influencia que es posible verificar a través de una serie de síntesis, de reciente publicación, que abordan el estudio del fenómeno resistente desde una perspectiva innovadora caracterizada por una permanente contraposición de su historia y memoria, a través de las cuales también el debate en torno a la definición de Resistencia se ha visto potenciado. ${ }^{6}$

De acuerdo con Olivier Wieviorka, atendiendo a esta evolución se imponen varias cuestiones: ¿debemos continuar centrando nuestros esfuerzos en proponer una nueva definición? O por el contrario, ¿deberíamos contentarnos con aportar un mayor grado de definición a los contornos del fenómeno resistente? ${ }^{7}$ Tener la libertad de elegir entre una y otra tarea, define plenamente la privilegiada situación que asiste a quienes -en la actualidad- aceptamos el reto de trabajar en torno a la historia de la Resistencia en Francia y de quienes la hicieron posible. Sin embargo, el contexto político-social francés de posguerra marcó tanto los límites de dicha definición, como los del marco legislativo en el que se apoyaron las autoridades francesas para clasificar, estudiar y evaluar el compromiso resistente de miles de ciudadanos franceses y extranjeros. Buena muestra de ello supone el análisis de los criterios para la atribución del título de deportado internado resistente (DIR). Condiciones que, si bien no acusan un grado de modificación tan acusado como las que han reglado la

\footnotetext{
${ }^{4}$ Pierre LABORIE, “Qu'est-ce que la Résistance ?" in François MARCOT (dir.), Dictionnaire historique de la Résistance, Paris, Robert Laffont, 2006, p. 33; François BÉDARIDA, "L'histoire de la Résistance. Lectures d'hier, chantiers de demain", Vingtième siècle, revue d'histoire,1 (1986), vol. 11, pp. 75-90.

${ }^{5}$ Ayla Aglan, Laurent Douzou, Olivier Wieviorka, Guillaume Piketty, Jean-François Muracciole, Denis Peschanski, Bruno Leroux, Stéphane Courtois o Daniel Cordier entre otros.

${ }^{6}$ Laurent DOUZOU, La Résistance française: une histoire perilleuse, Seuil, París, 2005; Olivier WIEVIORKA, Histoire de la Résistance, 1940-1945, Perrin, París, 2013; Laurent DOUZOU, y Tristan LECOQ, Enseigner la Résistance; Réseau Canopé, Lyon, 2016; Olivier WIEVIORKA, Une histoire de la Résistance en Europe occidentale, Perrin, París, 2017.
}

${ }^{7}$ Olivier WIEVIORKA, Histoire de la Résistance..., p.15. 
concesión del título de Combatiente Voluntario de la Resistencia $(C V R)^{8}$, se vieron influenciadas por la batalla político-conmemorativa que gaullistas y comunistas libraron en la posguerra mundial, especialmente a partir de 1947, año en que estos últimos fueron expulsados del gobierno. Una batalla en la que ambos trataron de imponer su particular lectura del pasado resistente, subrayando el compromiso de sus compañeros y camaradas en detrimento del protagonizado por sus -ahora- oponentes políticos, en pro de su respectiva legitimación como actores principales de una Resistencia censurada por ambos, pero también por un contexto político internacional de guerra fría al que nadie escapaba. ${ }^{9}$ No en vano, la elaboración de dos estatutos de deportado (internado resistente y político) supone un ejemplo paradigmático de dicha lucha. $\mathrm{Y}$ es que, mientras el Partido Comunista Francés (PCF) proponía un estatuto único basado en un concepto amplio de Resistencia, entendiendo a ésta como un movimiento patriótico y multifacético en el que combatientes y víctimas confluyen en un grupo y son asimiladas como resistentes; De Gaulle desarrolló un concepto de Resistencia restrictivo, militar y masculino del fenómeno que minimizaba la importancia de la Resistencia interior en la liberación del territorio nacional francés. ${ }^{10}$ Pese a que ambos relatos, gaullista y comunista, difieren en multitud de aspectos, coincidieron en una estrategia común: soterrar la participación extranjera en la Resistencia, y lo hicieron censurando sistemáticamente los recuerdos de posguerra de los franceses, olvidando y/o minimizando la participación de los extranjeros en la Resistencia y promocionando la imagen de un amplio consenso nacional enfrentado al ocupante. ${ }^{11}$

La guerra de Argelia (1954-1962) primero y la muerte del propio De Gaulle más tarde (1969) sacudieron los cimientos del "mito resistencialista" ${ }^{12}$, aunque este supo reinventarse, y lo hizo a través del culto a una "nueva" figura llamada -de nuevo- a

\footnotetext{
${ }^{8}$ Serge BARCELLINI, "Les resistants dans l'oeil de l'administration", Guerres mondiales et conflits contemporains, 178, 1995, pp. 141-165 ; Olivier WIEVIORKA, "Les avatars du statut résistant en France (1945-1992)", Vingtiéme siècle Revue d'histoire, nº 50, 1996, pp. 55-66.

9 Olivier WIEVIORKA, La mémoire désunie..., pp. 28-49, 62-66. Robert GILDEA, Fighters in the shadows. A new history of the French Resistance, Harvard University Press, 2015, pp.1-19.

${ }^{10}$ Olivier WIEVIORKA, La mémoire désunie, op. cit., p. 52-54.

${ }^{11}$ Olivier WIEVIORKA, "Du bon usage du passé. Résistance, politique, mémoire", in Mots. Les langages du politique, $\mathrm{n}^{\circ}$ 32, 1992, pp. 67-80; Geneviève DREYFUS-ARMAND, "Des étrangers Dans la Résistance", in CAESmagazine, n89, 2009, pp. 6-11.

${ }^{12}$ Henry ROUSSO, Le syndrome de Vichy, de 1944 à nos jours, Paris, Seuil, 1990, p. 19.
} 
"unirlos" a todos: Jean Moulin. Sin embargo, los extranjeros seguían sin entrar en la ecuación, es más, hubieron de esperar a la segunda mitad de la década de 1970 para hacerlo, momento en el que, por primera vez, un relato que subrayaba la importancia de antifascistas y judíos extranjeros en la Resistencia logró captar la atención de la opinión pública francesa. El mito evolucionaba y lograba integrar a los extranjeros en la empresa de la liberación sin abandonar por completo el chovinismo propuesto por gaullistas y comunistas. Francia había sido liberada por los franceses, pero no sin la ayuda de miles de resistentes extranjeros y judíos cuya participación había sido ocultada durante años.

\section{OLVIDO Y DESCONOCIMIENTO}

Formando parte de ese contingente de antifascistas foráneos, miles de españoles se comprometieron en la lucha contra la Alemania de Hitler ya fuese como "resistentes prematuros" -condición que presentan aquellos trabajadores y soldados españoles que combatieron a las tropas alemanas en la campaña 1939-1940- o como combatientes de la Resistencia interior y exterior "francesa" entre 1940-1945. ${ }^{13}$ Compromiso por el que, tal y como indicaba en inicio, más de 9.000 españoles fueron internados en campos nazis. Sin embargo, veinte años después del final de la guerra en Europa, su deportación continuaba siendo un tema desconocido tanto para la sociedad española en general, como para muchas familias que, a mediados de los años sesenta del pasado siglo, ignoraban que uno de sus miembros había sido internado y/o asesinado en uno de estos recintos. ${ }^{14}$

Pese a que oficialmente España se declaró país no beligerante durante el segundo conflicto mundial, la delicada situación que acuso el régimen de Franco en la inmediata posguerra española, el aislamiento internacional y el profundo deterioro de las relaciones diplomáticas con las potencias vencedoras en Europa, no facilitó el intercambio de información necesario para que muchas familias que continuaban buscando a uno o varios de sus miembros huidos, por norma general a Francia a

\footnotetext{
13 Diego GASPAR CELAYA, "Premature Resisters». Spanish Contribution to the French National Defence Campaign in 1939/1940 » in Journal of Modern European History, JMEH, 16 (2018), pp. 203 224.

${ }^{14}$ Benito BERMEJO y Sandra CHECA, Libro memorial..., p. 13.
} 
comienzos de 1939, lograsen encontrarlos. Ello sumado al retorno de los deportados españoles a Francia, a su tendencia al silencio y autocensura sobre su experiencia en deportación tampoco facilitaron el trabajo de quienes continuaban en su búsqueda. ${ }^{15}$ Muestra de ello, de la marginación que por parte del régimen de Franco recibieron éstos y otros asuntos relacionados con la deportación de españoles, y de que sólo a partir de los años sesenta el Holocausto y la arquitectura del terror nazis fuesen incorporados a la memoria colectiva de buena parte de las sociedades occidentales, incluida la española en exilio, supone el hecho de que tanto la primera obra de carácter memorial, como el primer trabajo profesional que abordaron el envío y encierro de españoles en campos nazis fueron publicados en Francia y Estados Unidos a comienzos de los años sesenta y finales de los setenta respectivamente. ${ }^{16}$ Aunque bien es cierto que, en este proceso también influyó la falta de interés social, tal y como revelan, por ejemplo, las dificultades que tanto Primo Levi como Gustaw Herling tuvieron para publicar sendos trabajos acerca de sus experiencias en campos nazis y el Gulag respectivamente. ${ }^{17}$

Al igual que sucediera con la llegada masiva de refugiados españoles a Francia provocada por la Guerra Civil y la participación de estos en la Resistencia en Francia, la deportación española no llamó la atención de los historiadores franceses y españoles hasta finales de los años ochenta y comienzos de los noventa, razón por la cual, en un primer momento, el desarrollo de una bibliografía dedicada a describir el itinerario vital y la experiencia de aquellos que fueron a parar a campos nazis se hizo posible gracias al concurso de sus propios protagonistas, la mayoría de ellos exiliados y/o resistentes. Así las cosas, a partir de 1969, vieron la luz, en Francia, las primeras obras elaboradas por responsables políticos, sindicales, escritores en las que sus autores describían su encierro en campos de internamiento, su trabajo en Compañías de Trabajadores Extranjeros (CTE) y Grupos de Trabajadores Extranjeros (GTE), su

\footnotetext{
${ }^{15}$ Alejandro BAER, Holocausto: recuerdo y representación, Madrid, Losada, 2006, pp. 63-64.

${ }^{16}$ Jorge SEMPRÚN, Le grand voyage, Paris, Gallimard, 1963; Louis STEIN, Beyond the death and exile. The Spanish republicans in France. 1939-1955, Cambridige, Harvard University Press, 1979.

17 Javier SÁNCHEZ ZAPATERO, El compromiso de la memoria: un análisis comparatista. Max Aub en el contexto europeo de la literatura del exilio y de los campos de concentración, Salamanca, Ediciones Universidad de Salamanca, 2009, p. 71.
} 
79compromiso con la Resistencia, y su supervivencia al infierno de los campos nazis. ${ }^{18}$ Años más tarde, un notable aumento de testimonios coincidió con la publicación de las primeras obras al sur de los Pirineos ${ }^{19}$ aunque, exceptuando las investigaciones de Louis Stein y David Wingeate Pike, lo cierto es que los primeros trabajos profesionales que abordan el estudio de la deportación española no aparecieron hasta mediada la década de $1970 .^{20}$

Hubo que esperar a finales de los años ochenta y comienzos de los noventa para que, de forma progresiva, numerosos proyectos, iniciados con anterioridad, se materializasen tanto en Francia como en España trayendo consigo un importante avance en el conocimiento del exilio y la deportación españoles. Sin embargo, no sería hasta 2006 cuando por fin vio la luz vio el Libro memorial, obra que recoge el trabajo que durante años llevaron a cabo Benito Bermejo y Sandra Checa, financiados por Ministerio de Cultura español, y que supuso un punto y aparte tanto en la identificación de deportados españoles, gracias al desarrollo de un proyecto propio en PARES y un motor de búsqueda en línea dedicado, como en la difusión y puesta en valor de la deportación española. Aunque cabe destacar en los últimos diez años trabajos de diferente entidad y naturaleza han contribuido a ampliar de manera significativa el conocimiento que tenemos sobre la deportación española y sus protagonistas. ${ }^{21}$

\footnotetext{
${ }^{18}$ Miguel RAZOLA y Mariano CONSTANTE, Triangle bleu. Les républicains espagnols à Mauthausen 1940-1945, París, Gallimard, 1969; Antonio VILANOVA, Los Olvidados. Los exiliados españoles en la Segunda Guerra mundial, París, Ruedo Ibérico, 1969; David WINGEATE PIKE, Vae Victis. Los republicanos españoles en Francia. 1939-1944, París, Ruedo Ibérico, 1969; Federica MONTSENY, Pasión y muerte de los españoles refugiados en Francia, Toulouse, Espoir, 1969.

19 Entre los principales trabajos que jalonaron este periodo encontramos: Alberto FERNÁNDEZ, Emigración republicana española. 1930-1945, Bilbao, Zero, 1972; Alberto FERNÁNDEZ, Españoles en la Resistencia, Bilbao, Zero, 1973; Eduardo PONS PRADES, Los que SI hicimos la guerra, Barcelona, Martínez Roca, 1973; Eduardo PONS PRADES, Republicanos españoles en la Segunda Guerra Mundial, Barcelona, Planeta, 1975; Eduardo PONS PRADES, Los cerdos del comandante, Barcelona, Argos Vergara, 1979.

20 Javier RUBIO, La emigración española a Francia, Barcelona, Ariel, 1974; Javier RUBIO, La emigración de la guerra civil de 1936-1939: historia del éxodo que se produce con el fin de la II República española (3 Vol.), Madrid, San Martín, 1977; José Luis ABELLÁN (ed.), El exilio español de 1939, Madrid, Taurus, 1976; Louis Stein, Beyond death and exile...

${ }^{21}$ Ángel DEL RÍO, Sandra CHECA y Ricardo MARTíN, Andaluces en los campos de Mauthausen, Sevilla, Centro de Estudios Andaluces, 2006; Manuel Alfonso ORTELLS, De Barcelona a Mauthausen. Diez años de mi vida (1935-1945), Madrid, Colección Memoria Viva Num. 5, 2007; Joan ESCUER GOMIS, Memoras de un deportado republicano español al campo de Dachau, Barcelona, Amical de Mauthausen, 2007; Mar TRALLERO, Neus Cátala. La dona antifeixista a Europa, Barcelona, Mina, 2008; Montserrat ARMENGOU, Ravensbrück.el infierno de las mujeres, Barcelona, Belacqua. 2008; Luiza
} 
Sumando mi esfuerzo al de quienes han hecho posibles los trabajos anteriormente mencionados, en este artículo presento el resultado del análisis de los 850 expedientes personales de españoles homologados como DIR por las autoridades francesas en posguerra que conserva el Service Historique de la Défense (SHD).

\section{DEPORTADO, INTERNADO, RESISTENTE: LÍMITES DEL ESTATUTO}

Tal y como apuntaba al inicio de este artículo, más de 9.000 españoles fueron internados en campos nazis durante el segundo conflicto mundial, cuya deportación es posible dividir en dos fases: 1940-1942; 1942-1945. Pese a que ambas tienen un denominador común: el inicio del "largo viaje" de sus protagonistas desde territorio francés, lo cierto es que poseen una serie de diferencias que al relacionarlas con los expedientes DIR analizados, ponen de manifiesto la relevancia de estos para ampliar nuestro conocimiento sobre la segunda fase de deportación española, en la que la mayoría de deportados españoles fueron enviados a campos nazis tras haber sido acusados de colaboración con la Resistencia. Expedientes que subrayan a su vez la condición de "resistentes prematuros" de aquellos españoles que fueron deportados en primera fase, dado que, pese a haber sido hechos prisioneros, en su mayoría, enfrentándose al ocupante mientras servían en Compañías de Trabajadores Extranjeros (CTE), dicho compromiso no fue interpretado en posguerra por las autoridades francesas como actividad resistente pese a su condición de prestatarios militares. $^{22}$

LORDACHE, Republicanos españoles en el Gulag (1939-1956), Madrid, Generic, 2009; Ernest GALLART VIVÉ, Kommando César. Los republicanos españoles en el sistema concentracionario del KL Mauthausen, Madrid, Memoria Viva, Monografías del Exilio español, Num. 9, 2011; Mercedes NÚÑEZ TARGA, Destinada al crematorio: de Argelès a Ravensbrück: las vivencias de una resistente republicana española, Sevilla, Editorial Renacimiento, 2011; Mercedes VILANOVA, Mauthausen, después. Voces de españoles deportados. Madrid, Cátedra, 2014; Benito BERMEJO, El fotógrafo del horror. La historia de Francisco Boix y las fotos robadas a los SS de Mauthausen, Madrid, RBA, 2015; Francisco AGRAMUNT LACRUZ, Arte en las alambradas. Artistas españoles en los campos de concentración, exterminio y gulags, Valencia, PUV, 2016; David SERRANO I BLANQUER, El Ilanto de la maleta. La historia de dos hermanas separadas tras el nazismo, Madrid, Milenio, 2016; Montserrat ROIG, Los catalanes en los campos de concentración nazis, Barcelona, Península, 2017; Carlos HERNÁNDEZ DE MIGUEL y loannes ENSIS, Deportado 4443. Sus tuits ilustrados. La historia de los 9.300 españoles cautivos en campos de concentración nazis, Barcelona, Ediciones B, 2017, entre otros.

\footnotetext{
${ }^{22}$ Diego GASPAR CELAYA, « Premature Resisters»...
} 
Entre 55.000 y 60.000 españoles sirvieron como prestatarios militares en estas CTE, teniendo como actividad principal la realización de trabajos de fortificación en sectores como la Línea Maginot, la frontera alpina franco-italiana y la frontera francobelga. En dichos sectores tomaron parte en la construcción de fosas antitanques, polvorines, trincheras, aeródromos, centrales hidroeléctricas, etc...,y/o en la reparación de carreteras y la tala de árboles. Pero, debido al emplazamiento geográfico asignado a las CTE empleadas en los sectores fronterizos, miles de ellos perdieron la vida o fueron hechos prisioneros combatiendo las tropas alemanas en mayo junio de $1940 .{ }^{23}$ Quienes cayeron en manos de las tropas enemigas, fueron, por norma general, internados en campos de prisioneros de guerra -Stalags ${ }^{24}$ condición a la que estaban sujetos los españoles por ser considerados prestatarios militares, pese a tener naturaleza civil. Como tales, compartieron reclusión, principalmente, con militares franceses y británicos, pero también con extranjeros de otras nacionalidades que habían servido a intereses franceses. En un primero momento, todos pudieron acogerse a los acuerdos internacionales que regulaban el tratamiento de prisioneros de guerra, pero meses después de haber sido internados, el ejército alemán cedió el control y la custodia de los prisioneros españoles a la GESTAPO, quien se encargó de separarlos del resto, recabar información sobre su procedencia y actividades políticomilitares en España y Francia, y finalmente deportarlos. ${ }^{25}$ De esta forma daba comienzo en agosto de 1940 la primera fase de la deportación española que se extendería en el tiempo hasta 1942 y en la que el destino del "largo viaje" de los deportados españoles quedó fijado en el campo de Mauthausen y sus anexos o kommandos en Austria, Alemania y Eslovenia.

Por el contrario, en segunda fase la deportación española se inscribe dentro de las medidas de represión aplicadas por las autoridades alemanas contra aquellos que habían participado en actividades contra el ocupante o integraban las filas de la

\footnotetext{
${ }^{23}$ Diego GASPAR CELAYA, La guerra continua. Voluntarios españoles al servicio de la Francia libre. 1940-1945, Madrid, Marcial Pons, 2015, pp. 129-153.

${ }^{24}$ El término stalag constituye la abreviatura de Stammlager: en alemán, campo para prisioneros de guerra (nombre completo Mannschaftsstamm und -straflager) lugares en los que se recluía, de acuerdo con la Convención de Ginebra de 1929 prisioneros de guerra, nunca civiles.

${ }^{25}$ Convención de Ginebra relativa al trato de prisioneros de guerra, Ginebra, 27 de julio de 1929. En vigor el 19 de junio de 1931. "International Humanitarian Law. Geneva Convention Prisioniers of War 1929." https://www.icrc.org
} 
Resistencia. Pasadores de fronteras, colaboradores de las redes de acción, información y evasión, editores y difusores de publicaciones clandestinas, agentes de la Resistencia interior y miembros de los GTE acusados de sabotaje, componen el amplio espectro español deportado en esta segunda fase, donde por primera vez están incluidas las mujeres. Aunque, a diferencia de lo ocurrido en la primera, la deportación de españoles aquí no comporta un caso específico de represión, sino que se inscribe en un marco más amplio en el que ciudadanos de todas las nacionalidades involucrados en actividades contrarias al ocupante en Francia fueron perseguidos, capturados y deportados. De modo que, pese a tener muy diferentes orígenes, quienes fueron deportados a partir de 1942 compartieron mayoritariamente un punto de partida común en su trayecto hacia los campos de concentración nazis: una primera reclusión en el Frontstalag 122 Compiègne, un campo de prisioneros situado a unos 87 kilómetros de París. Desde este recinto partieron rumbo a los campos nazis más de 1.000 españoles entre 1943 y 1944, aunque -a diferencia de lo ocurrido en la fase anterior- su destino no quedó fijado en un solo campo: Mauthausen, se vio diversificado. ${ }^{26}$

A priori, quienes fueron deportados en esta segunda fase, deberían de haber sido mayoritariamente homologados en posguerra como DIR. Sin embargo, el marco legal que define tanto las diferentes categorías o familias de resistencia resulta complejo. Tanto es así que, según establece la ley del 6 de agosto de 1948, es posible atribuir el título de DIR a toda persona que, por acto calificado de resistencia al enemigo, fue: transferido por el enemigo fuera del territorio nacional, y posteriormente encarcelado o internado, por un periodo mínimo de tres meses, en una prisión o un campo de concentración, y/o en un recinto sito otros territorios exclusivamente administrados por el enemigo. Mientras que en su artículo cuarto precisa que las personas arrestadas y ejecutadas por una acto calificado de resistencia al enemigo son consideradas como internadas resistentes, sea cual sea la duración de su detención, siempre que fuesen ejecutadas sobre el terreno. ${ }^{27}$ De modo que, atendiendo a estas y otras precisiones complementarias que aporta el resto del texto, cabe destacar que

\footnotetext{
${ }^{26}$ Un análisis exhaustivo de las fases de deportación españolas puede encontrarse en Benito BERMEJO y Sandra CHECA, Sandra, Libro memorial..., pp. 13-20.

${ }^{27}$ Loi $n^{\circ}$ 48-1251, 6 de agosto de 1948, publicada en el Journal Officiel de la République Française (JORF) el día 8 de agosto de 1948, pp. $7810-7811$; <http://www.legifrance.gouv.fr>
} 
ningún criterio de nacionalidad ${ }^{28}$ opera sobre los artículos que componen la ley, de modo que los españoles, internados y/o deportados conforme a las condiciones dispuestas, son susceptibles de poder recibir el título DIR, siempre que dicha detención y/o deportación se haya producido a consecuencia de un acto calificado de resistencia al enemigo. Aunque bien es cierto que dicha ley no comporta la atribución del título a todos los deportados internados resistentes, sino a aquellos capaces de demostrar que un acto de resistencia está en el origen de su detención y/o deportación. ${ }^{29}$ Una norma que, tal y como he precisado, estructura a su vez nuestra particular aproximación a la deportación española, y su diferenciación en fases.

Sin embargo, además de la ley del 6 de agosto, en la valoración de los "actos de resistencia contra el enemigo" resulta fundamental el análisis de otro texto: el código de pensiones militares de invalidez y de víctimas de guerra. El cual, en su el artículo R287, puntualiza que se considerarán actos calificados de resistencia al enemigo, siempre y cuando éstos se hayan desarrollados a partir del 16 de junio de 1940, los siguientes:

- El hecho de pertenecer a una de las redes, formaciones o movimientos, reconocidos por la autoridad militar, perteneciente a las Fuerzas Francesas Combatientes (FFC) a las Fuerzas Francesas del Interior (FFI) y/o a la Resistencia Interior Francesa (RIF).

- Todo acto calificado de acción contra el enemigo realizado en cumplimiento de las órdenes de los miembros de las redes, formaciones o movimientos anteriormente mencionados.

- Cualquier acto de ayuda voluntaria prestado a una red, una formación o un movimiento FFC, FFI o RIF o incluso individualmente a un miembro de dichos grupos.

- Todo acto realizados por cualquier persona asociada con la Resistencia que, por su importancia o sus repercusiones, hayan dañado gravemente el potencial de guerra del enemigo y que tuviesen este objetivo como motivo principal de la acción.

\footnotetext{
${ }^{28}$ Criterio que, por el contrario, sí que sanciona la ley del 9 de septiembre de 1948 para la atribución del título de deportado internado político.

${ }^{29}$ Dichos actos de Resistencia fueron regulados por el artículo R-287 del código de pensiones militares de invalidez y de víctimas de guerra, derogado el 1 de enero de 2017.<http://www.legifrance.gouv.fr>
} 
- Y finalmente todo acto, incluso aislado, de acción contra el enemigo, consistente consiste en: la redacción, impresión, transporte o distribución de folletos o periódicos clandestinos establecidos por una organización reconocida como se menciona en el punto primero. La producción, sin remuneración, de documentos de identidad de los miembros de la Resistencia. La fabricación y el transporte de equipos de radio para la transmisión y recepción de puestos clandestinos destinados a la Resistencia y el uso de dichos equipos. La provisión voluntaria y gratuita de una sala para la reunión de un grupo clandestino. El alojamiento gratuito para combatientes de la resistencia marcados o heridos, soldados franceses y/o aliados escapados o paracaidistas de los ejércitos aliados. El paso no remunerado de combatientes de la Resistencia y/o soldados aliados de territorio ocupado a la Francia libre, países aliados o no beligerantes. La destrucción o el sabotaje de cualquier medio o medio de comunicación, empresa o equipo que contribuya al esfuerzo bélico del enemigo. Acciones ofensivas $\mathrm{o}$ defensivas dirigidas contra las fuerzas militares enemigas 0 contra las autoridades $y / o$ cuerpos militares $y / o$ policiales bajo su control o las personas que colaboran con ellos. Un intento de abandonar un territorio ocupado por el enemigo o bajo el control de la autoridad de facto que se hace llamar gobierno del Estado francés [Vichy] o de un país no beligerante para unirse a los ejércitos de la Francia libre y/o, a partir del 8 de noviembre de 1942, a las fuerzas francesas estacionadas en África del norte o África occidental francesa y, posteriormente, a los ejércitos que quedaron bajo control del Comité Francés de Liberación Nacional primero, Gobierno Provisional de la República Francesa (GPRF) más tarde. ${ }^{30}$

De esta forma, atendiendo a los límites que marcan tanto la ley del 6 de agosto como el código de pensiones, todos aquellos que iniciaron su actividad resistente tras haber sido detenidos, es decir, durante su detención en Francia, su deportación o su liberación, no reúnen las condiciones necesarias para poder recibir dicho título. ${ }^{31}$ Ejemplo de ello constituye el caso de un militante comunista que, antes de la guerra y

\footnotetext{
${ }^{30}$ En tal caso, el interesado debe probar que se encontraba -antes de su intento de partida- en las condiciones previstas en el artículo R. 157 para incorporarse a dichas fuerzas o que pertenecía a una de las redes, formación o movimientos reconocidos como FFC, FFI o RIF. Artículo R-287 del código de pensiones militares de invalidez y de víctimas de guerra.<http://www.legifrance.gouv.fr>

31 Loi $\mathrm{n}^{\circ}$ 48-1251, 6 de agosto de 1948, JORF, 8 de agosto de 1948, pp. $7810-7811$; $<$ http://www.legifrance.gouv.fr>
} 
durante la ocupación, repartió propaganda y reparó armas para sus compañeros guerrilleros. A él, el Ministerio de Antiguos Combatientes denegó el título DIR, dado que la acción que motivó su deportación fue su pertenencia a un partido político: el Partido Comunista Francés. ${ }^{32}$ Mientras que por su parte, la historia del asturiano Ignacio Iglesias, nos sirve aquí para ilustrar un caso español. Miembro del Partido Obrero de Unificación Marxista (POUM) y redactor del diario La Batalla, Iglesias se exilio en Francia a comienzos de 1939. Activo colaborador de la dirección del partido en el exilio, fue detenido en 1941 por la policía de Vichy, y tras ser condenado por un tribunal militar, fue encarcelado en la central de Eysses, presidio situado en Villeneuvesur-Lot (Lot et Garonne) y en el que permaneció más de dos años hasta que fue deportado al campo de concentración de Dachau en junio de 1944, tras haber formado parte del motín que el 19 de febrero de 1944 protagonizaron en dicha prisión más de 1.400 internos, decenas de ellos españoles. Sin embargo, en posguerra, las autoridades francesas denegaron el titulo DIR a Iglesias pese a haber participado activamente en el motín de la prisión, dado que atendiendo a la norma su acción resistente -la participación en dicho motín- se había iniciado tras haber sido detenido. ${ }^{33}$

Entre las acciones que los españoles, y/ o sus familiares, declararon haber realizado frente a los técnicos del Ministerio de Antiguos Combatientes francés, encargados de la constitución y evaluación de los expedientes de deportado interno resistente, cruzar la línea de demarcación, proteger y guiar a resistentes "quemados" descubiertos por el enemigo- y soldados aliados a territorio "libre", falsificar documentación, habilitar espacios para reuniones clandestinas, sabotajes, o el desarrollo y difusión de propaganda sí son acciones tipificadas como actos de resistencia por el artículo R-287 del código. Sin embargo, a excepción de la Unión Nacional Española y su brazo armado (el XIV Cuerpo de Guerrilleros Españoles, posteriormente Agrupación de Guerrilleros Españoles) ninguna otra formación o movimiento de Resistencia español fueron reconocidos por las autoridades francesas

\footnotetext{
${ }^{32}$ Lucie HÉBERT, “Militer contre Vichy est-il un acte de résistance?",Cahiers d'histoire. Revue d'histoire critique, 128 (2015), pp. 127-141.

33 Josep SÁNCHEZ CERVELLO y Sebastián AGUDO BLANCO (dir.), Las brigadas internacionales: nuevas perspectivas en la historia de la guerra civil y del exilio, Tarragona, URV, 2015, pp. 311-312; W. SOLANO, "Ignacio Iglesias, escritor y antiguo dirigente del POUM", El País, 24 de octubre de 2005; Expediente Ignacio Iglesias Suarez, PARES: Españoles deportados a campos nazis (1940-1945); http://pares.mcu.es
} 
como organización o movimiento de Resistencia. De modo que, aplicando de nuevo los textos anteriores, todos aquellos españoles y españolas que llevaron a cabo una de las actividades anteriormente descritas en una red, formación o movimiento no integrada en las FFC, FFI o RIF, quedaron privados del derecho a optar al título DIR. Buen ejemplo de ello supone aquí el caso del aragonés Agustín Remiro Manero, colaborador del grupo de pasadores y guías de montaña que dirigía el anarquista Francisco Ponzán (Grupo Ponzán) en el Pirineo central, quien a su vez sirviera, junto a algunos de sus compañeros de grupo, en la red de evasión aliada (franco-británica) Pat O'Leary, reconocida como formación FFC. Miembro de la Confederación Nacional de Trabajadores (CNT), miliciano primero y posteriormente soldado republicano durante la contienda española, Agustín Remiro se exilió en Francia a comienzos de 1939. Internado en los campos de Argelès-sur-Mer y Mazères, en junio de 1939 Agustín se entrevistó con Ponzán quien inmediatamente lo integró en su grupo, tanto es así que el 3 de septiembre Remiro llevo a cabo su primera misión cerca de Berga. Buen conocedor de la frontera, Agustín continúo colaborado tanto con el Grupo Ponzán, como con los servicios secretos británicos en territorio francés, español y portugués. De hecho, a principios de 1941, cuando se encontraba desplazado en Lisboa fue detenido por la policía política portuguesa (PIDE) que, semanas después, lo entrego a la policía franquista. Encarcelado en España, fue condenado a muerte en abril de 1942, y pese a que el día de su ejecución intento la fuga, finalmente acabó suicidándose ante el acoso de sus captores. ${ }^{34}$

Sin embargo, pese a que Remiro fue detenido y condenado por una acto de resistencia tipificado en el artículo R-287, dado que el Grupo Ponzán no fue reconocido como formación FFC, FFI o RIF; de haber sobrevivido, nunca habría tenido derecho a optar al título DIR, pese a que su detención superase los noventa días y finalizase en su "ejecución". Aunque dada la calidad de país no beligerante tanto de Portugal -lugar de detención- como de la España franquista -lugar de la condena, ejecución y muerteel debate en torno al cumplimiento de las condiciones establecidas en la ley del 6 de agosto y el código de pensiones para la atribución del título DIR podría ampliarse

\footnotetext{
${ }^{34}$ Una completa biografía de Agustín Remiro puede encontrarse en: Antonio TÉLLEZ SOLÁ, Agustín Remiro. De la guerrilla confederal a los servicios secretos británicos, Zaragoza, ed. Ayuntamiento de Épila y Diputación de Zaragoza, 2006.
} 
reflexionando acerca de si un agente desplazado en misión, detenido y/o ajusticiado en territorio neutral o no declarado enemigo, es susceptible, siempre y cuando cumpla el resto de condiciones establecidas por ambos textos, de recibir el título de deportado, internado resistente.

Caso contrario constituye el de Alfonsina Bueno Vela, camarada de Remiro en el Grupo Ponzán quien, a diferencia de Remiro, además de desarrollar su actividad resistente en territorio francés, fue integrada en la red de evasión Pat O'Leary (formación reconocida FFC) en diciembre de 1941, tiempo este en el que Remiro ya llevaba más de 10 meses encerrado en una prisión franquista. Colaboradora junto a su padre y su marido de Grupo y red, ambos también deportados, Alfonsina fue detenida en Toulouse en octubre de 1943 y encerrada en la prisión de Saint Michel donde paso varios meses, hasta que en mayo de 1944 fue deportada al campo de Ravensbrück. Casi un año permaneció en dicho recinto hasta que en marzo de 1945 fue trasladada a Mauthausen junto a otras 2.500 prisioneras, de las que más de una treintena eran españolas. Allí se reencontró con su marido, Josep Ester i Borrás, detenido y deportado por pertenecer a Pat O'Leary, lo que a la postre le permitió obtener el título DIR. Evacuados por Cruz Roja Internacional el 22 de abril de 1945, Alfonisna fue condecorada por las autoridades británicas, norteamericanas y francesas por su participación en la Resistencia, y obtuvo el título DIR, dado que las autoridades francesas consideraron que sus actos de resistencia al enemigo en Pat O'Leary motivaron su detención y deportación. ${ }^{35}$

No obstante, para subrayar de nuevo el periodo mínimo de tres meses de detención y/o encarcelación, tal y como específica la ley del 6 de agosto, cabe destacar el caso de Eusebio Lopez, Laguarta, alias "Coteno", "Luis García" y/o "Salvador Ortega". Nacido en Fontanellas de Ayerbe (Huesca), Eusebio, de "confesión" anarquista, sirvió en España, junto a su hermano Pascual en el grupo de operaciones del Servicio de Información Especial Periférico (SIEP) del $10^{\circ}$ Cuerpo de Ejército

\footnotetext{
${ }^{35}$ Alfonsina Bueno Vela, SHD/GR, 16P 96209 y PARES: Españoles deportados a campos nazis (19401945); http://pares.mcu.es . Sobre la participación de Alfonsina Bueno y Josep Ester en la red Ponzán véase: María Fernanda MANCEBO, "Las mujeres españolas en la Resistencia francesa", Espacio, tiempo y forma, Serie V, Ha Contemporánea, t.9, (1996), pp. 239-256; Antonio TÉLLEZ SOLÁ, La Red de Evasión del Grupo Ponzán. Anarquistas en la guerra secreta contra el franquismo y el nazismo (19361944), Barcelona, Editorial Virus, 1996; Pilar PONZÁN, Lucha y muerte por la libertad. Memorias de nueve años de guerra, Barcelona, Tot Editorial, 1996.
} 
republicano que estuvo al mando de Francisco Ponzán. Exiliado en Francia a comienzos de 1939, Eusebio pasó por varios campos de internamiento hasta que en uno de ellos se alistó voluntario, como "Luis García" en la 191ª CTE. Desplazado junto a sus compañeros al departamento de Ariège, la compañía fue empleada en la construcción de una presa en el puerto de Siguer, en el límite con Andorra. Reclutado en fecha temprana por Ponzán para que formase parte de su "Grupo", Eusebio fue enviado en misión a España en repetidas ocasiones. ${ }^{36}$ Integrado en la red Pat O'Leary, Eusebio participó activamente en la evacuación de decenas de aviadores aliados y personas perseguidas por las autoridades alemanas hasta que el 14 de octubre de 1942, tras ser denunciado por un miembro de la red, fue detenido en Toulouse junto a su hermano Pascual, Francisco Ponzán, Vicente Moriones, José Luis Márquez Cuartero, José Albalat Ripollés, Amadeo Casares Colomer, Miguel Chueca y Pilar Ponzán. Trasladados a la jefatura de policía de la capital, todos ellos, a excepción de Ripollés, fueron internados en el campo de Le Vernet y liberados el 22 de diciembre de ese mismo año, gracias a una orden falsa de liberación emitida por el agente de la inteligencia gaullista Robert Terres, alias "el Padre", retomaron la actividad y la red doméstica volvió a funcionar a pleno rendimiento. Pero el 1 de abril de 1944, mientras Eusebio aguardaba la llegada de un agente de enlace, fue detenido de nuevo, esta vez por la GESTAPO en la estación de ferrocarril de Toulouse y acusado de pertenencia a la Resistencia. Sin embargo, aprovechando un descuido de sus captores logró escapar saltando por una ventana, contactó con un compañero de la red y fue evacuado al departamento del Ariège donde reanudó su actividad como pasador de fronteras. En total, permaneció encerrado 76 días, condición que le privó del derecho a obtener el título DIR para el que, como hemos visto, eran necesarios mínimo 90 días de internamiento y/o detención. ${ }^{37}$

Por último, el artículo R-287 del código de pensiones especifica que, para que puedan ser considerados como actos de resistencia al enemigo, éstos hubieron de

\footnotetext{
${ }^{36}$ H. HEINE, La oposición política al franquismo. De 1939 a 1952, Barcelona, Crítica, 1983, pp. 37-39; "Los orígenes de la "Alianza Democrática Española" hay que buscarlos en una iniciativa que en diciembre..." in Juan Carlos JIMÉNEZ DE ABERASTURI y Ricardo MORENO IZQUIERDO, Al servicio del extranjero. Historia del Servicio Vasco de Información. 1936-43, Antonio Macahdo Libros - Papeles del tiempo, Ebook.

${ }^{37}$ Datos biográficos de Eusebio López Laguarta extraídos de Antonio TÉLLEZ SOLÁ, La Red de Evasión del Grupo Ponzán....; y SHD/GR, 16P 330958.
} 
realizarse a partir del 16 de junio de 1940, es decir, seis días antes de que tuviese lugar la firma del Armisticio y dos antes de que el general De Gaulle llamase a los franceses a resistir desde Londres. No obstante, cabe destacar el extraordinario impacto que ésta fecha límite posee en la comunidad española deportada por dos razones. En primer lugar porque, todos aquellos que participaron activamente en la campaña 1939-1940, y fueron hechos prisioneros por ello no reúnen, dado que la fecha de su detención fue anterior al 16 de junio, las condiciones estipuladas por la ley para optar al título de deportados internados resistentes. $Y$ en segundo lugar, porque atendiendo al mensaje pronunciado por De Gaulle el 18 de junio de 1940, considerado como el texto fundador de la Resistencia "francesa"38, ello convierte en "resistentes prematuros" a todos aquellos españoles que se enfrentaron al enemigo antes de la fecha límite ya fuese en unidades de la Legión, en Regimientos de marcha de voluntarios extranjeros o en CTE. ${ }^{39}$

Uno de estos "resistentes prematuros" fue el prestatario cántabro Fernando Fernández Lavín, capturado, junto a varios de sus compañeros de CTE, por las tropas alemanas cerca de la Línea Maginot. Internado en el Stalag V-D de Estrasbugo (BasRhin), Fernández fue deportado a Mauthausen el 13 de diciembre de 1940, donde permaneció encerrado más de cuatro años y participó activamente: primero en la creación del Comité de Unidad Nacional español durante la primavera de 1944, organismo en el que estuvieron representados todos las tendencias políticas españolas y cuya dirección fue compartida por miembros del Partido Comunista Español (PCE), la CNT y el Partido Socialista Obrero Español. Posteriormente en la constitución del Comité Internacional de presos de Mauthausen. $\mathrm{Y}$ finalmente en la fundación del Aparato Militar Internacional (AMI) cuya dirección compartió junto a otro español Miguel Malle- y al general soviético Andrei Pirógov. Organización de resistencia transnacional que alcanzó un alto grado de visibilidad especialmente durante los últimos días de encierro y los primeros de libertad que vivieron los presos de

\footnotetext{
${ }^{38}$ Charles DE GAULLE, Mémoires de guerre : L'Appel, 1940-1942, París, Plon, 1954, pp. 69-71; François DELPLA, L'Appel du 18 juin 1940, París, Grasset, 2000; Olivier WIEVIORKA, Histoire de la Résistance. 1940-1945, París, Perrin, 2013, pp. 7-29.
}

${ }^{39}$ Diego GASPAR CELAYA, « Premature Resisters».... 
Mauthausen. ${ }^{40}$ Sin embargo, pese a la destacada contribución de Fernando Fernández en ella, sus servicios no le habilitaron a recibir el título de deportado internado resistente dado que, no fueron estos los que motivaron su detención e internamiento. Fue su oposición como prestatario militar y su condición de "combatiente de la España roja" las que propiciaron su captura y deportación respectivamente. Además, dado que ambas, se produjeron con anterioridad al 16 de junio de 1940, quedaron también excluidas por la ley de 6 de agosto de 1948 como actos de resistencia al enemigo que dan acceso a la atribución del título DIR atendiendo a dicha fecha ${ }^{41}$.

\section{CONSTITUCIÓN, CONSERVACIÓN Y EVALUACIÓN DE EXPEDIENTES}

Desde que finalizase la Segunda Guerra Mundial, la responsabilidad de la evaluación y homologación de los servicios prestados por un voluntario, nacional (francés) o extranjero, a la Resistencia ha recaído en diferentes comisiones y órganos administrativos que ha evolucionado, al tiempo que lo han hecho las políticas oficiales de memoria en Francia. ${ }^{42}$ No en vano, al concluir el conflicto, la nueva Administración francesa se dotó de una legislación que permitiese el reconocimiento de los servicios prestados por quienes se comprometieron en la lucha contra el ocupante y sus socios. Con el fin de poder analizar y resolver la multitud de casos particulares y su heterogeneidad, las autoridades francesas implementaron una clasificación de las múltiples formas de resistencia practicadas en un número limitado de categorías o familias. En un primer grupo quedaron encuadradas las familias de naturaleza puramente civil: combatientes voluntarios de la Resistencia (CVR), refractarios del Servicio del Trabajo Obligatorio (STO), deportados políticos, refugiados de Alsacia y la Mosela, etc. Mientras que en un segundo grupo quedaron cinco de naturaleza mixta (civil y/o militar) que se distinguen por los servicios, fundamentalmente militares, prestados por sus integrantes, estas son: las FFI, maquis y unidades militarizadas;

\footnotetext{
${ }^{40}$ Carlos HERNÁNDEZ DE MIGUEL, Los últimos españoles de Mauthausen, Barcelona, Ediciones B, 2015, pp. 378-381; ficha detallada de Fernando Fernández Lavín en PARES: Españoles deportados a campos nazis (1940-1945); http://pares.mcu.es;

${ }^{41}$ Loi $n^{\circ}$ 48-1251, 6 de agosto de 1948, publicada en el Journal Officiel de la République Française (JORF) el día 8 de agosto de 1948, pp. 7810 -7811; <http://www.legifrance.gouv.fr>

${ }^{42}$ Olivier WIEVIORKA, La mémoire désunie. Le souvenir politique des années sombres de la Libération a nos jours, París, Seuil, 2010; Robert Gildea, Figthers in the shadows....
} 
FFC, miembros de redes de información, acción y evasión; FFL, personal de los ejércitos franceses libres; RIF, miembros de movimientos de la Resistencia cuyos servicios justifican una pensión militar; y por último, el caso que nos ocupa, los deportados e internados resistentes o DIR.

Más de 70.000 expedientes personales de hombres y mujeres, deportados internos resistentes componen el cuerpo de archivo de la familia deportada en el que he podido identificar a 850 resistentes nacidos en España (796 de ellos hombres, 93,5\%; 54 mujeres, 6,5\%) Aunque cabe destacar que, por norma general, quienes pertenecen a ésta categoría, también lo hacen a una de las anteriores. En nuestro caso, de los 850 deportados internados resistentes nacidos en España, 513 (60,3\%) figuran además como miembros de otras familias de resistencia y se distribuyen del siguiente modo: 95 (18,5\% de 513 totales) FFC; 299 (58,3\%) FFI; 147 (27,8\%) RIF y únicamente dos $(0,38 \%) \mathrm{FFL}$, que también pertenecen a la categoría $\mathrm{FFC}^{43}$ Ello me permite destacar el peso específico que tuvo la participación española en la Resistencia interior en Francia (FFI, FFC, RIF) en el conjunto general de detenciones y encierro de españoles a consecuencia de actos calificados de resistencia, en detrimento de su rama exterior (FFL). Datos que ponen de manifiesto, tanto la "protección" que aportó el alistamiento en un ejército regular a los españoles que sirvieron en las FFL frente a la deportación, como el riesgo al que se expusieron aquellos que, abrazando la clandestinidad, contribuyeron a la lucha resistente como miembros de una formación y/o movimiento de Resistencia FFI o FFC. Aunque cabe subrayarse aquí que los dos españoles DIR homologados también como FFL, abrazaron igualmente la clandestinidad para servir como agentes permanentes en una red reconocida por el Comité Nacional Francés.

Éste fue el caso de Santiago Sabater, nacido en Badalona (Barcelona) en 1910, se incorporó a la red evasión Bourgogne en febrero de 1943 en la que sirvió, en concreto en el sector de Perpiñán, hasta que el 24 de junio de ese mismo año fue detenido por las tropas nazis. Internado en prisión pasó más de nueve meses hasta que el 9 de marzo de 1944 fue deportado. No regresó, falleció el 8 de mayo de 1945 en deportación. Asimilado con el grado de subteniente, el título deportado internado

\footnotetext{
${ }^{43}$ Datos y cálculos extraídos y operados sobre el total de deportados internados resistentes nacidos en España identificados en el SHD. SHD/GR, 16P. 1459 - 16P 605622
} 
resistente le fue atribuido en marzo de 1952, tal y como precisa su certificado de validación de servicios, campañas y heridas de guerra. Documento que también precisa la atribución, por parte de las autoridades civiles francesas, de la mención Mort pour la France (Muerto por Francia) según establecen los criterios expuestos en los artículos L-488 - L-492, del anteriormente citado código de pensiones militares de invalidez y de víctimas de guerra. Aunque, cabe destacar que, pese a que Santiago Sabater también prestó servicio para la red de información y evasión Maurice, dependiente del Servicio de camuflaje de material (CDM), fueron los llevados a cabo como agente $\mathrm{P} 2$ de Bourgogne los que permiten que sus servicios sean homologados como FFL, en tanto en cuanto dicha red fue reconocida como tal a fecha 10 de diciembre de 1953 por las autoridades militares francesas. ${ }^{44}$

No obstante, al hilo de los datos analizados, resulta sorprendente que únicamente dos FFL españoles hayan obtenido el título de deportado interno resistente, máxime cuando casos como los del ilerdense Luis Rosell o del granadino Antonio Valenzuela muestran con claridad cómo miembros de la Resistencia exterior permanecieron durante más de tres meses encerrados en diferentes campos y/o presidios enemigos. En el caso de Rosell y Valenzuela, concretamente en el campo de prisioneros de Bérgamo donde ambos fueron internados tras haber sido capturados por tropas ítalo-germanas el 11 de junio de 1942 en Bir-Hakeim (Libia). No en vano, ambos pertenecían a la misma unidad: la $13^{\text {a }}$ semi-brigada de la Legión extranjera francesa (13é DBLE $)^{45}$ en la que sirvieron cientos de españoles. Internados en un primer momento en un improvisado campo de prisioneros en Bengasi (Libia), de allí fueron trasladados en barco a Italia a mediados de agosto. Sin embargo, el control que ejercían las tropas británicas en el Mediterráneo obligó al transporte a desviarse hacia Patras (Grecia) tras ser torpedeado el día 17 de ese mismo mes. Así las cosas, tras permanecer una semana en territorio griego, el convoy de prisioneros zarpó de nuevo y alcanzó Bari (Italia) el día 28 de agosto, desde donde los prisioneros fueron trasladados al campo de prisioneros número 62 de Bérgamo, última escala común de nuestros dos protagonistas ya que Antonio Valenzuela fue posteriormente trasladado al

\footnotetext{
${ }^{44}$ SHD/GR, 16P 528779

45 Abreviación de su nomenclatura original francesa: 13éme Demi-brigade de la Lègion Étrangère. Unidad que a su vez formaba parte, durante la campaña de Libia, de la $1^{\text {a }}$ Brigada francesa libre (1ere Brigade Française libre, 1ere BFL) que dirigía el general Koënig.
} 
Stalag VII-A situado en Moosburg a.d. Isar ( Alemania) donde permaneció internado hasta ser liberado por las tropas aliadas en abril de 1945. Mientras que Luis Rosell, logró evadirse del campo de prisioneros de Bérgamo un año más tarde, unirse a la Resistencia italiana y, tras contactar con las tropas francesas que participaron en la liberación de Italia, volver a ser integrado en la 13é DBLE, unidad en la que de la que fue desmovilizado al terminar el conflicto ${ }^{46}$.

\section{ITINERARIOS DE EXILIO, RESISTENCIA Y DEPORTACIÓN}

Tal y como apuntaba al inicio, los expedientes de españoles deportados internos resistentes suponen una nueva fuente para el estudio de la deportación española, especialmente en segunda fase. Tanto es así que, al relacionar los datos que estos aportan, con los recogidos en el Libro memorial, en su versión corregida en web en PARES, me ha sido posible comprobar, en primer lugar, que el $40 \%$ de los españoles homologados como DIR fueron deportados a campos nazis, especialmente a Dachau, Buchenwald y Neuengamme, de los que más de un $87 \%$ de ellos logró salir con vida. $Y$ en segundo lugar que más de un $95 \%$ de ellos fueron deportados en 1944, y que un $75 \%$ tuvo como punto de partida de su "largo viaje" el Frontstalag $\mathrm{n}^{\circ} 122$ de Compiègne.

Pero además de su estudio cuantitativo, el estudio individual de los expedientes DIR ofrece la posibilidad de reconstruir el itinerario vital y de resistencia de sus titulares en el periodo 1939-1945, tal y como ha quedado demostrado en los casos individuales a los que he hecho referencia. De modo que, un análisis detallado del total de expedientes nos permitiría analizar la fecha y el lugar de nacimiento del resistente, su estado civil, su profesión, la formación, movimiento, organización o unidad en la que presto servicio, la actividad con la que contribuyó, el grado o grado de asimilación militar alcanzado, la fecha de entrada a la Resistencia, la fecha de su detención, las circunstancias en que se produjo, el periodo (s) que permaneció internado, el centro o centros donde cumplió su condena y la fecha de su deportación, entre otros datos de interés que, tal y como hemos visto nos es posible completar a su vez con los archivos

\footnotetext{
${ }^{46}$ Luis Rosell, SHD/GR, 16P 520312; Antonio Valenzuela, SHD/GR, 16P 582807.
} 
de PARES. Aunque, bien es cierto que no todos los expedientes presentan un mismo grado de detalle, dado que no todos conservan los mismos documentos.

Entre los más de ochocientos expedientes de españoles deportados internados resistentes estudiados, me detendré aquí en el análisis de cinco de ellos con el doble objetivo de: en primer lugar ilustrar la pertenencia de éstos a otras categorías resistentes, y en segundo lugar reconstruir los itinerarios de vida y resistencia de sus titulares. De modo que, para ilustrar la experiencia de vida y muerte de dos deportadas internadas resistentes Carmen Bartoli y Sabina González Bártoli, madre e hija, ambas nacidas en Nacidas en Setcases (Gerona), y homologadas también como FFI y FFC respectivamente, ambas deportadas a Ravensbrück acusadas de pertenencia a la Resistencia. Emigradas económicas junto al resto de su familia a Valmanya (Pyrénées Orientales, PO) en 1929, diez más tarde allí les sorprendió la guerra de nuevo, y allí comenzaron a colaborar con la Resistencia de la región desde fecha temprana. Tanto es así, que en junio de 1941 Carmen y Sabina ya colaboraban activamente con diferentes movimientos que operaban en la región (Combat, Franc-Tireur y LibérationSud) alojando, escondiendo y alimentando a algunos de sus miembros. Actividad que fue en aumento convirtiendo la casa familiar de Valmanya en pieza clave en la acogida y ayuda al maquis de la zona, pero también a agentes de información, pasadores y fugitivos, huéspedes especialmente numerosos tras la incorporación de Sabina a las redes Darius (finales de 1942) y Sabot (mayo 1943), y al Estado Mayor de Armée Sécrete (a comienzos de agosto de 1943).

Dicha actividad llamó la atención de las fuerzas de ocupación que en agosto de 1943 detuvieron e internaron a madre e hija en la cárcel de Amélie-les-Bains-Palada (PO) primero, y en la ciudadela de Perpiñán (PO) más tarde, hasta que fueron trasladadas a Compiègne a finales de enero de 1944. A penas tres días permanecieron en el campo de prisioneros cercano a París, ya que el 3 de febrero de ese mismo año ambas fueron deportadas a Ravensbrück en el transporte más numeroso salido desde Francia hacia este campo. ${ }^{47}$ Recinto en el que, recordemos, también fue internada

\footnotetext{
${ }^{47}$ Montserrat ROIG, Els catalans als camps nazis, Barcelona, Edicions 62, 1977, p. 785; Neus CATALÁ, De la resistencia y la deportación. 50 testimonios de mujeres españolas, Barcelona, Península, 2000, pp. 159-160; VV.AA., Livre-mémorial des déportés de France arrêtés par mesure de répression et dans certains cas per mesure de persécution 1940-1945, París, Tirésias, 2004, p. 182; Benito BERMEJO y Sandra CHECA, Libro memorial..., p.493. Expediente de Sabina González Bartoli, SHD/GR, 16P 36213.
} 
Neus Catalá, quien recordaba así el "largo viaje" que compartiera con Carmen y Sabina hasta Ravensbrück:

De allí [Compiègne] saldríamos, hacia Ravensbrück, Coloma Seros, Carmen Cuevas, Amalia Perramón, Sole, Herminia Martorell, Rosita Da Silva, Alfonsina Bueno, Sabina González y su madre Carmen Bartolí, Carlota Olaso, Rita Pérez y otras que no tuve tiempo de conocer. Cinco días estuvimos esperando y vislumbrando que lo que habiamos sufrido no era nada para lo que nos esperaba. Hacinadas, viviamos de un cuarto de pan y de agua por día, para beber y lavarnos. Sin higiene y sin aire, aquello fue la antecámara de la muerte [...] seríamos embarcadas casi 1000 mujeres en vagones de ganado; 80 mujeres en cada vagón. [...] Nuestros bártulos: un cubo de carburo vacío para nuestras necesidades, que se vertía constantemente encima de un puñado de paja, por litera. Una aspillera de $50 \times 30 \mathrm{~cm}$. nos suministraba el aire que por turno íbamos a respirar. Sin comer y sin beber, asi estuvimos tres días. ${ }^{48}$

Encerradas en Ravensbrück, permanecieron juntas apenas dos meses hasta que Carmen falleció a comienzos de abril de 1994, en los brazos de otra compañera española integrante del mismo transporte: Coloma Serós. Por su parte Sabina fue trasladada meses más tarde al campo de Flossenbürg, donde ingresó el 1 de septiembre de 1944, y desde donde fue inmediatamente trasladada al kommando de Helmbrechts para ser empleada en una fábrica de munición. Liberada el 5 de mayo de 1945 , fue repatriada a Francia, y en posguerra, las autoridades francesas además de homologar sus servicios como FFC, FFI, le concedieron el título de deportada internada resistente.

Por su parte, para abordar el caso de deportados internados resistentes españoles cuyos servicios fueron homologados como FFC analizaré los ejemplos de José Albalat Ripollés y Carmen Aguilera Zapater, ambos deportados y sobrevivientes al campo nazi de Mauthausen. José Albalat Ripollés, nacido en Albocàsser en 1912, llegó a Francia a comienzos de 1939 tras haber participado activamente en la Guerra Civil española. Ebanista de profesión, de pensamiento anarquista y amigo de Francisco Ponzán, fue uno de los primeros en comprometerse con el "Grupo" que dirigía el maestro anarquista. Tanto es así que, en mayo de 1940, ayudó a Ponzán y a tres compañeros más a cruzar por el Pirineo aragonés hasta Boltaña (Huesca). Integrado, junto a otros miembros del Grupo Ponzán en la red de evasión Pat O'Leary,

\footnotetext{
${ }^{48}$ Neus CATALÁ, De la resistencia y la deportación..., pp. 159-160.
} 
colaboró en la evacuación de aviadores aliados y fugitivos buscados por la GESTAPO y las autoridades de Vichy. Sin embargo, el 14 de octubre de 1942, tras ser denunciado por un miembro de la red, fue detenido en Toulouse junto a varios compañeros. Trasladados a la jefatura de policía primero y posteriormente encerrados en el campo de Le Vernet, todos fueron liberados el 22 de diciembre de ese mismo año, gracias a una orden falsa redactada por Robert Terres, agente doble de la inteligencia de Vichy. Todos menos José, dado que un error en la redacción de dicha orden impidió su puesta en libertad. Enviado a trabajar a Saint-Jean-de-Luz (Pyrénées Atlantiques) por las autoridades alemanas, logró evadirse y se instaló en Perpiñán (PO) desde donde continuó su actividad como pasador de frontera, esta vez al servicio de la red Kléber subred Vénus hasta que fue detenido de nuevo el 31 de octubre de 1943 cuando se disponía a atravesar la frontera. Enviado al Stalag XII-F de Saarbrücken, fue deportado a Mauthausen el 29 de abril de 1944, donde ingresó con la matrícula 64.542. Liberado el 6 de mayo de 1945, fue repatriado a Francia veinte días más tarde y se instaló de nuevo en Toulouse. Sus servicios en Kléber como agente P2 permitieron su homologación como FFC y posteriormente como deportado internado resistente. $^{49}$

Carmen Aguilera Zapater, nacida en Sevilla a finales de mayo de 1912, de profesión mecanógrafa y costurera, madre de tres hijos, viuda y residente en Perpiñán (PO) antes de que se declarasen las hostilidades, ingresó en las filas de la Resistencia, como agente de la red de evasión Alibi, posteriormente integrada en Maurice, a comienzos de febrero de 1942. Especializada en la ocultación, alojamiento y cuidado de soldados británicos y franceses, y de agentes de enlace, pese a iniciar su actividad resistente como agente ocasional (PO), en el plazo de apenas un año se comprometió plenamente alcanzando el grado P2. Sin embargo, una mayor exposición y riesgo, propiciaron también su detención a manos de la GESTAPO el 31 de diciembre de 1943. Permaneció encerrada en la prisión de Toulouse más de siete meses, hasta que el 15 de julio de 1944 fue deportada al campo de Ravensbrück, donde ingresó con la matrícula número 49676. Trasladada a Mauthausen en marzo de 1945, logró

\footnotetext{
${ }^{49}$ Ferrán SÁNCHEZ AGUSTÍ, Espías, contrabando, maquis y evasión: la Segunda Guerra Mundial en los Pirineos, Lérida, Milenio, 2003, p. 216. Ficha detallada de José Albalat Ripollés en PARES: Españoles deportados a campos nazis (1940-1945); http://pares.mcu.es Expediente personal de José Albalat Ripollés, SHD/GR, 16P 201.
} 
sobrevivir, fue liberada a comienzos de mayo y repatriada el 21 día a Francia. Instalada de nuevo en Perpiñán, tardó más de dos años en recuperarse físicamente de su paso por los campos nazis, tiempo este en el que Carmen, además de acudir a periódicas revisiones médicas en París, consiguió reunir la documentación necesaria para que sus servicios como resistente fuesen homologados por las autoridades militares como FFC y obtener el título de deportada internada resistente. ${ }^{50}$

Finalmente, presento el caso de Pedro Bonet Cuito como ejemplo de la pertenencia de un deportado internado resistente español a la categoría RIF. Nacido en Lérida a mediados de mayo de 1901, tipógrafo de profesión, casado y padre de un hijo, Pedro se exilió en Francia en enero de 1939 tras haber escapado de la prisión en la que cumplía condena por traición. Sindicalista y político, co-fundador de los semanarios Lucha Social (1919), órgano de la CNT de Lérida y La Batalla (1922), Pedro, miembro del Comité Ejecutivo del Bloque Obrero y Campesino (BOC) y de la Alianza obrera de Cataluña (1933), militó en UGT y participó en la fundación del POUM, siendo elegido miembro de su Comité Ejecutivo en septiembre de 1935. Detenido en Barcelona tras las jornadas de Mayo de 1937 fue condenado por traición y espionaje a quince años de prisión. Encarcelado primero en la prisión de Las Corts, y posteriormente en Cadaqués, logró evadirse de ésta junto al resto de dirigentes del partido, a excepción de Nin, que muriese preso en Alcalá de Henares, gracias a la colaboración de sus guardianes. Descubiertos por un comando del Partido Socialista Obrero y Campesino francés (PSOP) dirigido por el escritor Daniel Guerin y Maurice Jaquier, al intentar pasar la frontera en enero de 1939, fueron detenidos y encerrados en campos de internamiento de los que pronto lograron salir, gracias a la colaboración ofrecida por el PSOP, que facilitó también su traslado e instalación en París, ciudad donde tuvo lugar la primera reunión del Comité Ejecutivo del POUM en el exilio, celebrada en casa del escritor belga Víctor Serge, amigo de Nin y Maurín. ${ }^{51}$

Ya en libertad, Bonet se trasladó de nuevo al sur de Francia, en concreto a Toulouse, donde a partir de noviembre de 1941 comenzó a colaborar, como pasador

\footnotetext{
${ }^{50}$ Ficha detallada de Carmen Zapater Aguilera en PARES: Españoles deportados a campos nazis (1940-1945); http://pares.mcu.es Expediente personal de Carmen Zapater Aguilera en SHD/GR, 16P 4262.

${ }^{51}$ Geneviève DREYFUS-ARMAND, L'exil des républicains espagnols en France. De la guerre civile à la mort de Franco, París, Albin Michel, 1999, p.91.
} 
de fronteras, con los movimientos de Resistencia L'Insurgé de Lyon y Libérer et Fédérer de Toulouse. Arrestado el 13 de febrero de 1942 por la policía de Vichy, fue internado en la prisión de St. Michel, pero tras seis meses de encierro, fue trasladado al islote de vigilancia especial del campo de internamiento de Récébédou (Haute Garonne), desde donde fue trasladado, en diciembre de ese mismo año, al campo de Le Vernet. Calificado como "Internado Político", el 3 de agosto de 1943 fue, trasladado a Bordeaux (Gironde) junto con otros 200 internos que habían sido seleccionados por las autoridades alemanas para trabajar en las obras que la Organización Todt, el ente empresarial creado por la Alemania nazi para la explotación de mano de obra esclava, llevaba a cabo en la ciudad del Garona. Sin embargo, a finales de agosto de 1943, logró eludir su incorporación a la Todt gracias a una rápida maniobra que le permitió emplearse en la ciudad, circunstancia que le permitió también ponerse de nuevo en contacto con antiguos camaradas resistentes que facilitaron su vuelta a la actividad resistente, esta vez al servicio de la red de Pimento de la sección F del Special Operations Executive (SOE) británico, más conocida como Buckmaster. En ella sirvió como agente P1 desde el 1 de enero de 1943 hasta el 30 de septiembre de 1944. La validación de dichos servicios en posguerra supusieron la homologación de Pedro Bonet Cuito como RIF y FFC. ${ }^{52}$

\section{CONCLUSIONES}

Tal y como hemos visto, establecer una definición de Resistencia ha sido -y continúa siendo- una tarea compleja dada la diversidad y heterogeneidad de formas en las que se manifestó el fenómeno resistente y el contexto político-social de posguerra. Buena muestra de ello supone el análisis de los criterios para la atribución del título de deportado internado resistente aquí expuestos, los cuales, tal y como hemos visto, se vieron influenciados por la batalla político-conmemorativa que a partir de 1947 libraron gaullistas y comunistas tratando de imponer su particular lectura del pasado resistente. Una batalla que dio como resultado -además de la elaboración de los dos estatutos de deportado internado: resistente y político- una definición restrictiva, militar y masculina del fenómeno resistente, base del aparato legislativo implementado en posguerra en el

\footnotetext{
${ }^{52}$ Expediente personal Pedro Bonet Cuito, SHD/GR, 16P 70005.
} 
que las autoridades francesas se han basado a la hora de evaluar y reconocer el compromiso de miles de resistentes, nacionales y extranjeros. Una definición que sentó las bases de la exclusión de los opositores políticos al gaullismo -especialmente los comunistas- del estatus de deportado internado resistente tal y como hemos podido comprobar en los casos anteriormente mencionados de un propagandista comunista francés y del poumista Ignacio Iglesias. Ejemplos que a su vez ponen de manifiesto como la lucha política continuó a través, tanto de la aplicación práctica de los textos, como de la composición de las comisiones encargadas de la atribución del título de deportado internado resistente. De hecho, dichas comisiones tuvieron como componente principal a los representantes de la Federación nacional de deportados e internados resistentes (FNDIR), en la que gaullistas, socialistas y demócrata-cristianos eran mayoría, muy por delante de los miembros de la primera Federación de deportados en número de adherentes a nivel nacional: la Federación nacional de deportados e internados resistentes patriotas (FNDIRP) de obediencia comunista, cuya presencia en estas comisiones fue marginal. ${ }^{53}$

Sin embargo, pese a las muchas y diferentes las posibilidades que ofrece el estudio de los expedientes de españoles DIR, lo cierto es que, atendiendo al propio estatuto que los regula, a la legislación que rige su atribución, y a la interpretación que de la norma han hecho las autoridades francesas; ha quedado demostrado que tanto los límites de la definición legislativa de Resistencia, como la severidad de las comisiones encargadas de examinar las peticiones de atribución del título DIR impidieron que miles de opositores políticos (al gaullismo) lograsen ser reconocidos como DIR, y que todos aquellos que hicieron frente al enemigo con anterioridad al 16 de junio de 1940 o con posterioridad a su detención, quedasen también privados del derecho a acogerse a dicho estatuto y optar al título DIR. Este fue, tal y como hemos visto, el caso de miles de españoles deportados a Mauthausen entre 1940 y 1942. Aunque a ellos podemos sumar cientos de compatriotas arrestados e internados por su "sospechosa" condición política por el gobierno de la III República francesa y/o por el régimen de Vichy; o por éste último y/o las tropas de ocupación, acusados de haber participado en actos de resistencia que, o bien los textos de la ley y el código de pensiones no contemplan como tales, o bien se realizaron formando parte de una

\footnotetext{
${ }^{53}$ Lucie HÉBERT, “Militer contre Vichy..."pp. 137-141.
} 
estructura o formación que tampoco éstos consideran como resistente. Condiciones que a su vez sirvieron como base de la exclusión de miles de guerrilleros y militantes clandestinos españoles del estatus de deportados internado resistentes, apelando a la naturaleza política de su actividad o a que ésta se realizó en el seno de una organización y/o movimiento no reconocido por el GPRF. Argumentos que ignoran por completo el contexto en el que se produjo el "salto" a la clandestinidad de estos hombres y mujeres, su compromiso y oposición al ocupante y sus socios; al tiempo que continúan preconizando una lectura elitista, restrictiva y militar de la Resistencia en Francia.

De modo que, si bien la documentación que contienen los más de ochocientos cincuenta expedientes analizados nos permite profundizar en los itinerarios vitales y actos de resistencia protagonizados por sus titulares, en los motivos de su detención y/o en el periodo y lugares en el que transcurrió su internamiento y su deportación. Tal y como ha quedado demostrado, el estatuto de deportado internado resistente en sí, y la aplicación restrictiva de los textos que rigen sobre su atribución por parte de las autoridades francesas, han contribuido tanto al desconocimiento del resto de deportados españoles, en primera y segunda fase, como al del miles de resistentes, franceses y extranjeros, detenidos e internados y/o deportados a consecuencia de un compromiso resistente "menor", de su pertenencia a una organización resistente no reconocida por las autoridades francesas en posguerra, o fruto de un acto de resistencia no validado por estas una vez que los cañones hubieron enmudecido en Europa. 


\section{BIBLIOGRAFÍA CITADA}

- ABELLÁN, José Luis (ed.), El exilio español de 1939, Madrid, Taurus, 1976.

- AGRAMUNT LACRUZ, Francisco, Arte en las alambradas. Artistas españoles en los campos de concentración, exterminio y gulags, Valencia, PUV, 2016.

- ARMENGOU, Montserrat, Ravensbrück.el infierno de las mujeres, Barcelona, Belacqua. 2008.

- BAER, Alejandro Holocausto: recuerdo y representación, Madrid, Losada, 2006.

- BARCELLINI, Serge, "Les resistants dans l'oeil de l'administration", Guerres mondiales et conflits contemporains, 178, 1995, pp. 141-165

- BÉDARIDA, François, 'L'histoire de la Résistance. Lectures d'hier, chantiers de demain", Vingtième siècle, revue d'histoire,1 (1986), vol. 11, pp. 75-90.

- BERMEJO, Benito y CHECA, Sandra, Libro memorial. Españoles deportados a los campos nazis (1940-1945), Madrid, Secretaría General Técnica. Subdirección General de Archivos Estatales, 2006.

- BERMEJO, Benito, El fotógrafo del horror. La historia de Francisco Boix y las fotos robadas a los SS de Mauthausen, Madrid, RBA, 2015.

- Carlos HERNÁNDEZ DE MIGUEL, Los últimos españoles de Mauthausen, Barcelona, Ediciones B, 2015.

- CATALÁ, Neus, De la resistencia y la deportación. 50 testimonios de mujeres españolas, Barcelona, Península, 2000.

- DE GAULLE, Charles, Mémoires de guerre : L'Appel, 1940-1942, París, Plon, 1954.

- DEL RÍO, Ángel, Sandra CHECA y Ricardo MARTíN, Andaluces en los campos de Mauthausen, Sevilla, Centro de Estudios Andaluces, 2006.

- DELPLA, François, L'Appel du 18 juin 1940, París, Grasset, 2000.

- DOUZOU, Laurent y LECOQ, Tristan, Enseigner la Résistance; Réseau Canopé, Lyon, 2016. 
- DOUZOU, Laurent, La Résistance française: une histoire perilleuse, Seuil, París, 2005.

- DREYFUS-ARMAND, Geneviève, "Des étrangers Dans la Résistance", in CAESmagazine, n89, 2009, pp. 6-11.

- DREYFUS-ARMAND, Geneviève, L'exil des républicains espagnols en France. De la guerre civile à la mort de Franco, París, Albin Michel, 1999.

- ESCUER GOMIS, Joan, Memoras de un deportado republicano español al campo de Dachau, Barcelona, Amical de Mauthausen, 2007.

- FERNÁNDEZ, Alberto, Emigración republicana española. 1930-1945, Bilbao, Zero, 1972

- FERNÁNDEZ, Alberto, Españoles en la Resistencia, Bilbao, Zero, 1973.

- GALLART VIVÉ, Ernest, Kommando César. Los republicanos españoles en el sistema concentracionario del KL Mauthausen, Madrid, Memoria Viva, Monografías del Exilio español, Num. 9, 2011.

- GASPAR CELAYA, Diego, «Premature Resisters». Spanish Contribution to the French National Defence Campaign in 1939/1940 » in Journal of Modern European History, JMEH, n. 16 (2018), pp. 203 - 224.

- GASPAR CELAYA, Diego, La guerra continua. Voluntarios españoles al servicio de la Francia libre. 1940-1945, Madrid, Marcial Pons, 2015.

- GILDEA, Robert, Fighters in the shadows. A new history of the French Resistance, Harvard University Press, 2015.

- HÉBERT, Lucie, "Militer contre Vichy est-il un acte de résistance ?", Cahiers d'histoire. Revue d'histoire critique, 128 (2015).

- HEINE, Hartmut, La oposición política al franquismo. De 1939 a 1952, Barcelona, Crítica, 1983.

- HERNÁNDEZ DE MIGUEL, Carlos y ENSIS, loannes, Deportado 4443. Sus tuits ilustrados. La historia de los 9.300 españoles cautivos en campos de concentración nazis, Barcelona, Ediciones B, 2017. 
- IORDACHE, Luiza, Republicanos españoles en el Gulag (1939-1956), Madrid, Generic, 2009.

- JIMÉNEZ DE ABERASTURI, Juan Carlos y MORENO IZQUIERDO, Rafael, Al servicio del extranjero. Historia del Servicio Vasco de Información. 1936-43, Antonio Macahdo Libros - Papeles del tiempo, Ebook.

- LABORIE, Pierre, "Qu'est-ce que la Résistance ?" in François MARCOT (dir.), Dictionnaire historique de la Résistance, Paris, Robert Laffont, 2006.

- MANCEBO, María Fernanda, "Las mujeres españolas en la Resistencia francesa", Espacio, tiempo y forma, Serie V, $\mathrm{H}^{\mathrm{a}}$ Contemporánea, t.9, (1996), pp. 239256.

- MONTSENY, Federica, Pasión y muerte de los españoles refugiados en Francia, Toulouse, Espoir, 1969.

- NÚÑEZ TARGA, Mercedes, Destinada al crematorio: de Argelès a Ravensbrück: las vivencias de una resistente republicana española, Sevilla, Editorial Renacimiento, 2011.

- ORTELLS, Manuel Alfonso, De Barcelona a Mauthausen. Diez años de mi vida (1935-1945), Madrid, Colección Memoria Viva Num. 5, 2007.

- PONS PRADES, Eduardo Los cerdos del comandante, Barcelona, Argos Vergara, 1979.

- PONS PRADES, Eduardo, Los que SI hicimos la guerra, Barcelona, Martínez Roca, 1973.

- PONS PRADES, Eduardo, Republicanos españoles en la Segunda Guerra Mundial, Barcelona, Planeta, 1975.

- PONZÁN, Pilar, Lucha y muerte por la libertad. Memorias de nueve años de guerra, Barcelona, Tot Editorial, 1996.

- RAZOLA, Manuel y CONSTANTE, Mariano, Triangle bleu. Les républicains espagnols à Mauthausen 1940-1945, París, Gallimard, 1969.

- ROIG, Montserrat, Els catalans als camps nazis, Barcelona, Edicions 62, 1977. 
- ROIG, Montserrat, Los catalanes en los campos de concentración nazis, Barcelona, Península, 2017.

- ROUSSET, David, L'Univers concentrationnaire, 1946, París, Éditions de Minuit, 1965.

- ROUSSO, Henry Le syndrome de Vichy, de 1944 à nos jours, Paris, Seuil, 1990, p. 19.

- RUBIO, Javier La emigración de la guerra civil de 1936-1939: historia del éxodo que se produce con el fin de la Il República española (3 Vol.), Madrid, San Martín, 1977.

- RUBIO, Javier, La emigración española a Francia, Barcelona, Ariel, 1974

- SÁNCHEZ AGUSTÍ, Ferrán, Espías, contrabando, maquis y evasión: la Segunda Guerra Mundial en los Pirineos, Lérida, Milenio, 2003.

- SÁNCHEZ CERVELLO, Josep y AGUDO BLANCO, Sebastián (dir.), Las brigadas internacionales: nuevas perspectivas en la historia de la guerra civil y del exilio, Tarragona, URV, 2015.

- SÁNCHEZ ZAPATERO, Javier, El compromiso de la memoria: un análisis comparatista. Max Aub en el contexto europeo de la literatura del exilio y de los campos de concentración, Salamanca, Ediciones Universidad de Salamanca, 2009, p. 71.

- SEMPRÚN, Jorge, Le grand voyage, Paris, Gallimard, 1963.

- SERRANO I BLANQUER, David, El llanto de la maleta. La historia de dos hermanas separadas tras el nazismo, Madrid, Milenio, 2016

- SOLANO, Wildebaldo, "Ignacio Iglesias, escritor y antiguo dirigente del POUM", El País, 24 de octubre de 2005.

- SOLZHENITSYN, Aleksandr Isaevich, Archipiélago Gulag : Ensayo de investigación literaria : 1918-1956, Barcelona, Tusquets, 2005.

- STEIN, Louis, Beyond the death and exile. The Spanish republicans in France. 1939-1955, Cambridige, Harvard University Press, 1979. 
- TÉLLEZ SOLÁ, Antonio, Agustín Remiro. De la guerrilla confederal a los servicios secretos británicos, Zaragoza, ed. Ayuntamiento de Épila y Diputación de Zaragoza, 2006.

- TÉLleZ SOLÁ, Antonio, La Red de Evasión del Grupo Ponzán. Anarquistas en la guerra secreta contra el franquismo y el nazismo (1936-1944), Barcelona, Editorial Virus, 1996.

- TRALLERO, Mar, Neus Cátala. La dona antifeixista a Europa, Barcelona, Mina, 2008

- VILANOVA, Antonio, Los Olvidados. Los exiliados españoles en la Segunda Guerra mundial, París, Ruedo Ibérico, 1969.

- VILANOVA, Mercedes, Mauthausen, después. Voces de españoles deportados. Madrid, Cátedra, 2014.

- VV.AA., Livre-mémorial des déportés de France arrêtés par mesure de répression et dans certains cas per mesure de persécution 1940-1945, París, Tirésias, 2004.

- WIEVIORKA, Olivier, "Du bon usage du passé. Résistance, politique, mémoire", in Mots. Les langages du politique, $\mathrm{n}^{\circ}$ 32, 1992, pp. 67-80

- WIEVIORKA, Olivier, "Les avatars du statut résistant en France (1945-1992)", Vingtiéme siècle Revue d'histoire, n 50, 1996, pp. 55-66.

- WIEVIORKA, Olivier, Histoire de la Résistance, 1940-1945, Perrin, París, 2013.

- WIEVIORKA, Olivier, La mémoire désunie. Le souvenir politique des années sombres de la Libération a nos jours, París, Seuil, 2010.

- WIEVIORKA, Olivier, Une histoire de la Résistance en Europe occidentale, Perrin, París, 2017.

- WINGEATE PIKE, David, Españoles en el holocausto. Vida y muerte de los republicanos en Mauthausen, Barcelona, Mondadori, 2003.

- WINGEATE PIKE, David, Vae Victis. Los republicanos españoles en Francia. 1939-1944, París, Ruedo Ibérico, 1969. 